Advances in Gene Technology: The Genome and Beyond -

Structural Biology for Medicine (Proceedings of the 2002 Miami

Nature Biotechnology Winter Symposium)

TheScientificWorld 2002, 2(S2), 62-64

ISSN 1532-2246; DOI 10.1100/tsw.2002.31

\title{
SECONDARY STRUCTURE CHANGES IN A CALCIUM BINDING PROTEIN: CENTRIN
}

\author{
Belinda Pastrana-Rios, Zuleika Medina, and Wanda Ocaña \\ Department of Chemistry, University of Puerto Rico Mayagüez Campus, Mayagüez, Puerto Rico \\ 00681-9019 \\ Belinda@hpcf.upr.edu
}

INTRODUCTION. Centrin is a low-molecular-weight $(20-\mathrm{kD})$, protein that belongs to the EFhand superfamily of calcium-binding proteins. Local and overall changes were investigated for interactions between cations and phosphorylated and unphosphorylated Chlamydomonas centrin using Fourier transform infrared (FT-IR) spectroscopy. FT-IR spectral features studied included Amide I' band and the side-chain absorbance for aspartate the residues located almost exclusively at the calcium-binding sites in the spectral region of $1700-1500 \mathrm{~cm}^{-1}$. The Amide I' band is exquisitely sensitive to changes in protein secondary structure and is often used to monitor changes in protein conformation. These spectral bands are complex and were further studied using two-dimensional FT-IR (2D-FT-IR) correlation along with curve-fitting routines. Using these methods the secondary structure contributions were determined for holo- and apo-centrin in its unphosphorylated form and phosphorylated holo-centrin. Thermal dependence revealed reversible melting with transition temperatures for each form of the protein also the phosphorylated holoprotein did not change significantly the secondary structure of the protein.

METHOD. Chlamydomonas centrin was overexpressed off a pt7-5 plasmid construct in E. coli BL21 $\lambda \mathrm{DE}_{3}$ induced with IPTG (Gibco BRL, Ann Arbor, MI) to yield milligram quantities of the desired protein. The bacterial cells were lysed and the resulting supernatant was subjected to affinity column chromatography and strong anion exchange column chromatography. The purified sample was analyzed by SDS-PAGE, Western Blot, TOF-MS, and partial amino acid sequencing revealing the protein to be $>99 \%$ pure.

To generate the phosphorylated protein, the sample was incubated at $30^{\circ} \mathrm{C}$ with protein kinase A (PKA), DTT, and ATP overnight. Phosphorylated and the unphosphorylated samples were then extensively dialyzed against the appropriate buffer for each experiment: (1) FT-IR experiments of holo-centrin or phosphorylated holo-centrin would require $50 \mathrm{mM}$ Hepes buffer containing $4 \mathrm{mM}$ $\mathrm{CaCl}_{2}, 4 \mathrm{mM} \mathrm{MgCl}_{2}$, and $150 \mathrm{mM} \mathrm{NaCl}$ at $\mathrm{pH}$ 7.4; and (2) FT-IR experiments of apo-centrin 50 $\mathrm{mM}$ Hepes buffer containing $4 \mathrm{mM}$ EGTA, $4 \mathrm{mM}$ EDTA, and $150 \mathrm{mM}$ at pH 7.4 (3) for the titration experiments the dialyzed apo-centrin was subjected to a second dialysis with $50 \mathrm{mM}$ Hepes buffer containing 2 mM EGTA, 2 mM EDTA, and $150 \mathrm{mM}$ at pH 7.4.

Spectra were collected following complete $\mathrm{H} \rightarrow \mathrm{D}$ exchange in the centrin preparation. The sample was deposited between two $25 \mathrm{~mm} \mathrm{CaF} 2$ or $\mathrm{AgCl}_{2}$, windows with a 40- $\mu \mathrm{m}$ spacer. A reference 
cell was prepared similarly. The instrument was an FTS-40 Bio-Rad (Cambridge, MA) or a Mattson Infinity Series with custom sample shuttle and interface. Typically, 512 scans were coadded, apodized with a triangular function, and Fourier transformed to provide a resolution of 4 $\mathrm{cm}^{-1}$ with data encoded every $2 \mathrm{~cm}^{-1}$. For the thermotropic studies, spectra were collected at sequential increments of temperature, allowing for equilibrium, and used in the 2D-FT-IR correlation analysis.

2D-FT-IR correlation analysis was performed using MathCad 2000 (MathSoft, Inc., Cambridge, MA) software. The curve-fitting routines were done using Grams (Galactic Industries Corp., Salem, NH) program. Origin 6 program was used to plot curve-fitted data.

RESULTS. The titration of apo-centrin as analyzed by 2D correlation analysis (Fig. 1) revealed the sequential secondary structure changes that occur during calcium binding and confirmed the apo- and holo-spectral features observed for this protein.

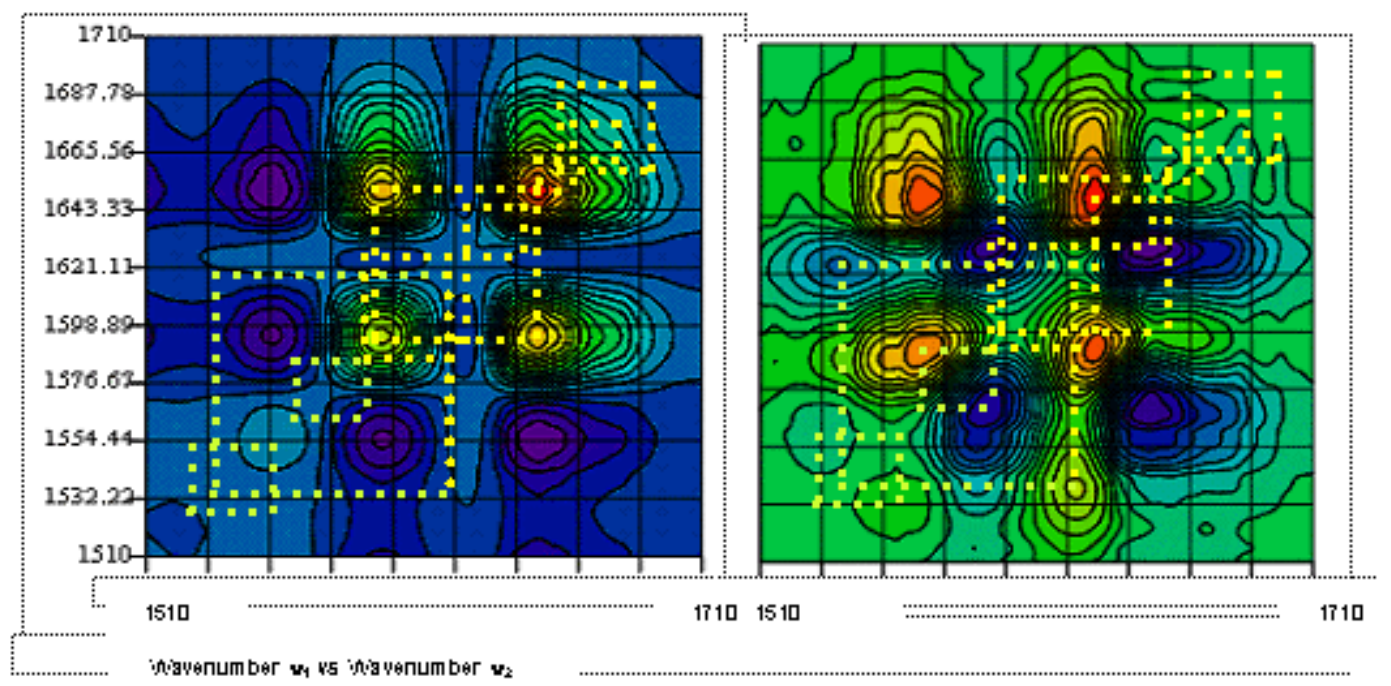

FIGURE 1. 2D correlational plots for the calcium titration experiment of Ccen; (a) synchronous and (b) asynchronous plot.

In addition, as shown in Fig. 2 the spectral features for apo-, holo-, and phosphorylated holocentrin.

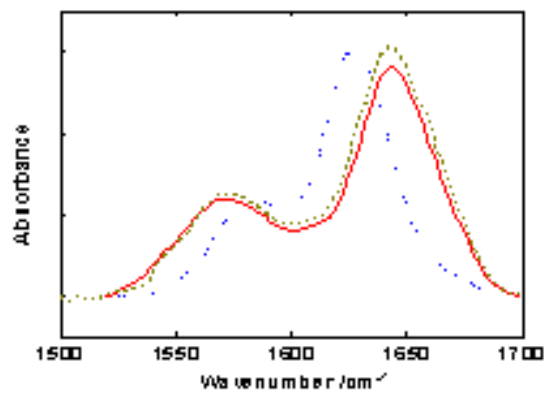


FIGURE 2. Superimposed spectra of the three forms of Ccen; (blue) apo-centrin, (red) holocentrin, (gold) phosphorylated holo-centrin.

DISCUSSION. There are small changes in the spectral features of the Amide I' band when spectra obtained in the presence of cations yet the differences observed in the absence of cations are dramatic. Suggesting that there are secondary structural changes and different self-association states for this protein.

\section{REFERENCES}

1. Huang, B., Mengersen, A., and Lee, V.D. (1988) [pdb AC: P05434] J. Cell Biol. 107, 133-140.

2. Moncrief, N., Kretsinger, R., and Goodman, M. (1990) J. Mol. Evol. 30, 522562.

3. $\quad$ Salisbury, J.L. and Floyd, G. (1978) Science 202, 975-977.

4. Weber, C., Lee, V.D., Chazin, W.J., and Huang, B. (1994) J. Biol. Chem. 269, 15795-15802.

5. Wiech, H., Geier, M.B., Paschke, T., Spang, A., Grein, K., Steinkotter, J., Melkonian, M., and Schiebel, E. (1996) J. Biol. Chem. 271, 22453-22461.

6. Lutz, W., Lingle, W.L., McCormick, D., Greenwood, T.M., and Salisbury, J.L. (2001) J. Biol. Chem. 276, 20774-20780. 

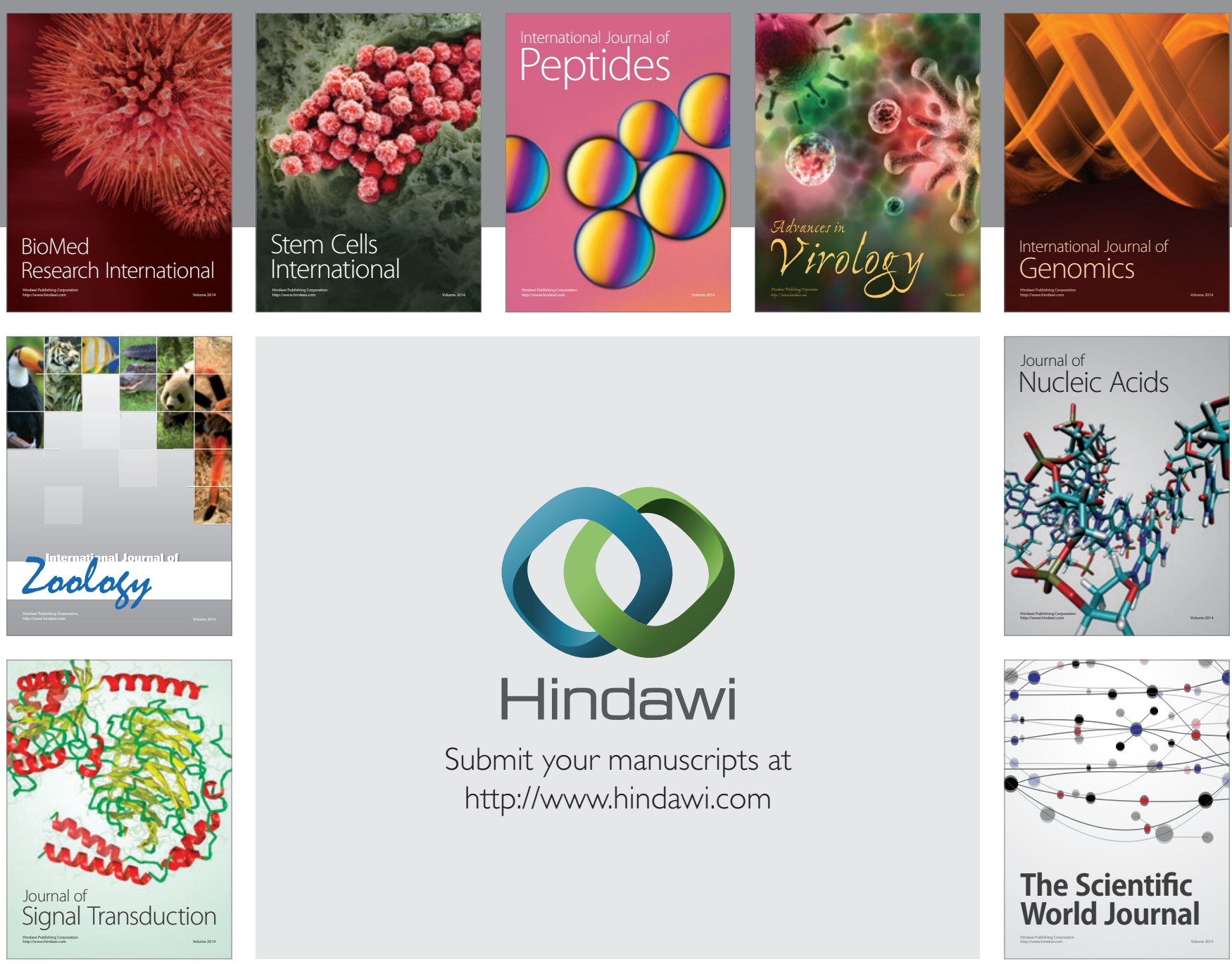

Submit your manuscripts at

http://www.hindawi.com
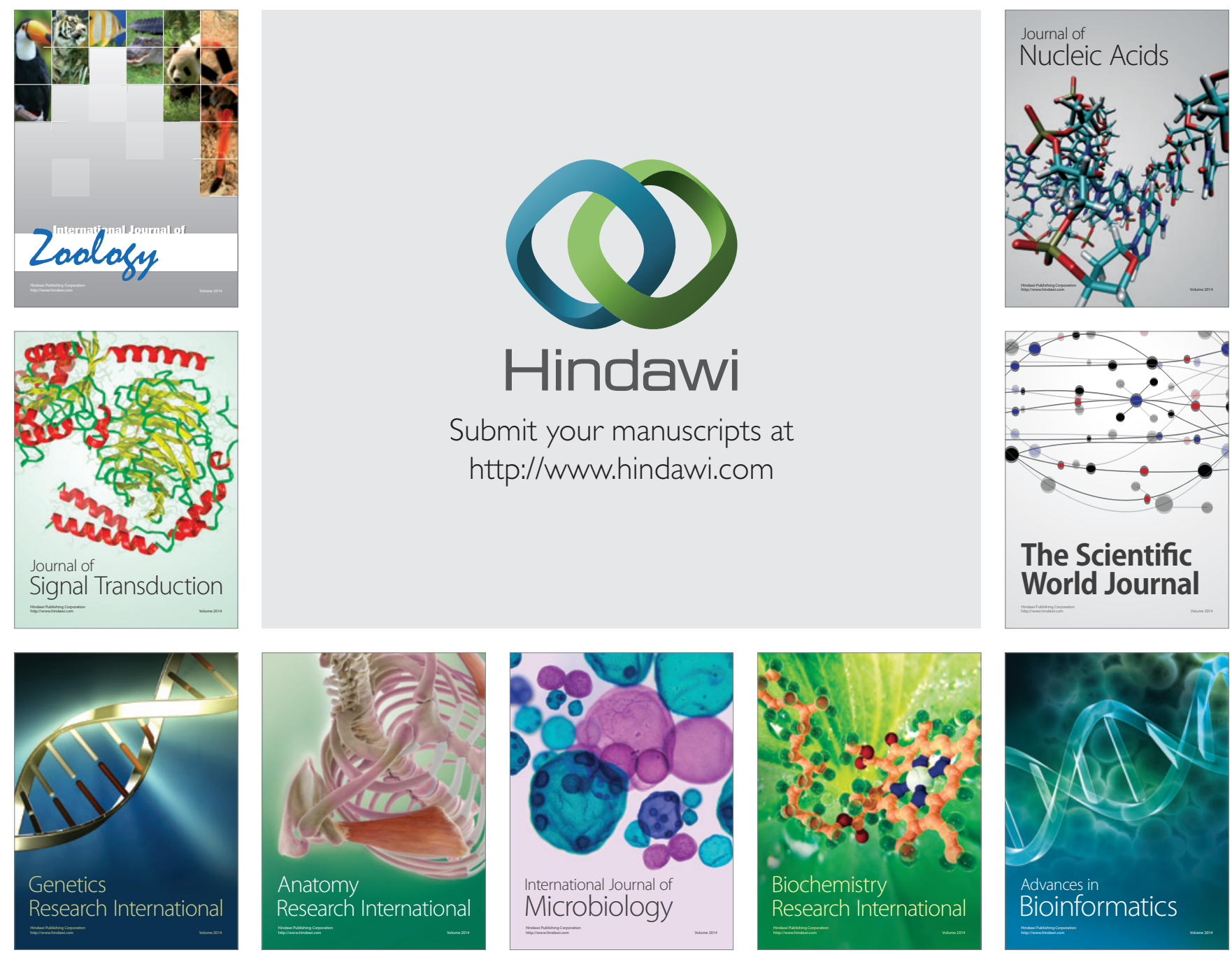

The Scientific World Journal
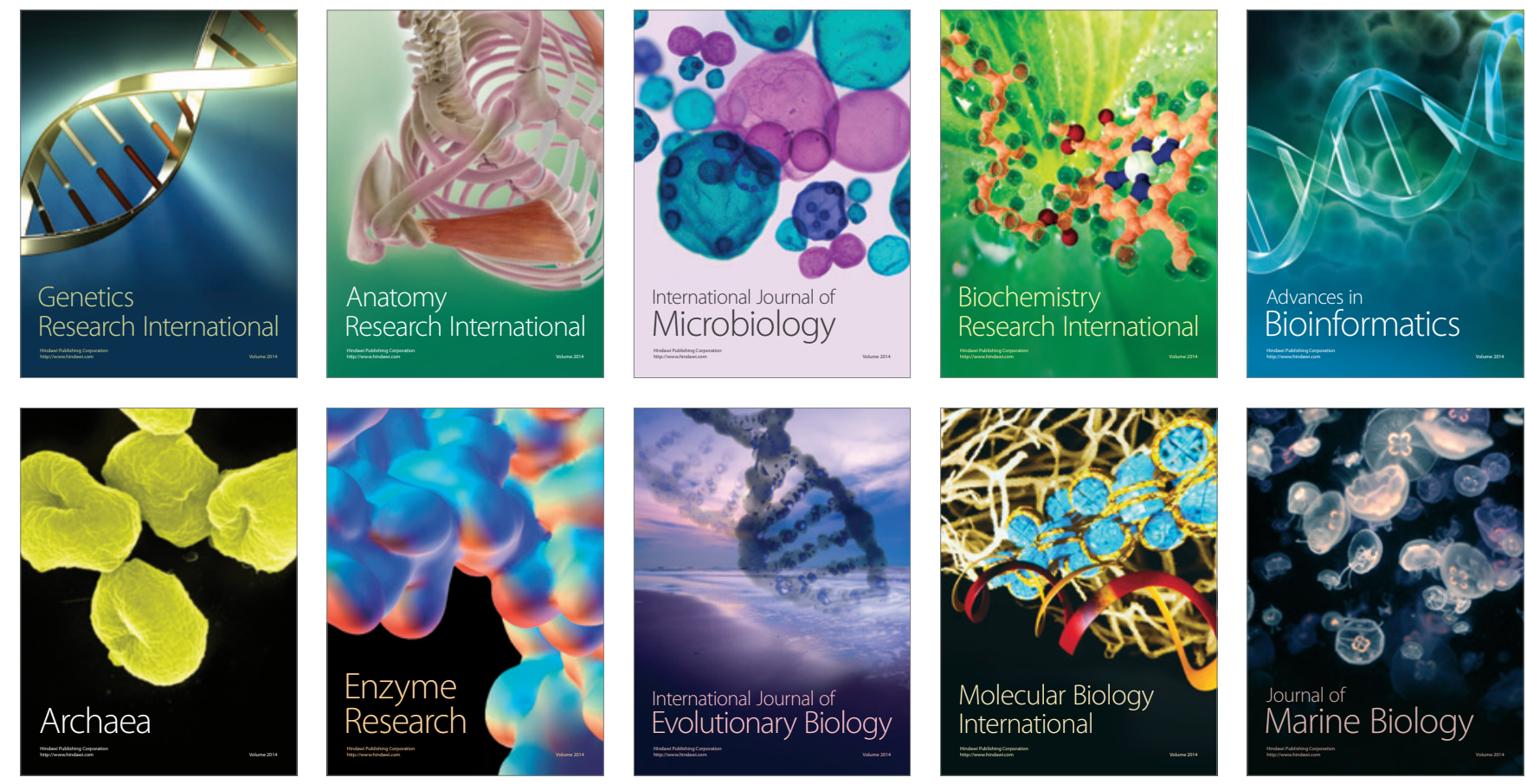